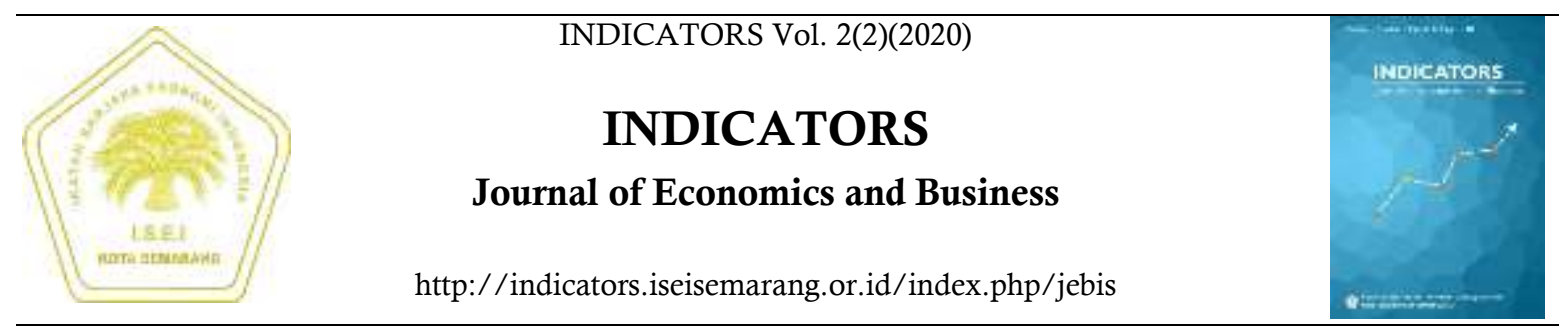

\title{
PENERAPAN PERATURAN PEMERINTAH NO. 23 TAHUN 2018 DAN UNDANG - UNDANG NO. 36 TAHUN 2008 DALAM PENGELOLAAN LABA PERUSAHAAN
}

\author{
Henri Erwanto ${ }^{1}$, Kesi Widjajanti ${ }^{2 凶}$, Dyah Nirmala $^{3}$ \\ ${ }^{1,2,3}$ Program Magister Manajemen, Universitas Semarang
}

\section{Info Artikel}

Sejarah Artikel:

Diterima Agustus 2020

Disetujui September 2020

Dipublikasikan

November 2020

\section{Keywords:}

PP no. 23/2018, UU no.

36/2008, Pengelolaan Lab,

Laba Perusahaan

\begin{abstract}
Abstrak
Tujuan penelitian ini adalah menganalisis pemahaman terhadap Peraturan Pemerintah no. 23 tahun 2018 dan Undang - Undang no. 36 tahun 2008, menganalisis perbandingan biaya pajak penghasilan berdasarkan Peraturan Pemerintah no. 23 tahun 2018 dengan Undang - Undang no. 36 tahun 2008, menganalisis implementasi peraturan - peraturan tersebut dan menganalisis saat yang tepat untuk mengimplementasikan Peraturan Pemerintah no. 23 tahun 2018 dan Undang - Undang no. 36 tahun 2008. Penelitian ini menggunakan pendekatan kualitatif, yaitu teknik penelitian dengan cara menganalisa $\mathrm{p}$ elaporan perpajakan berdasarkan Undang - Undang no. 36 tahun 2008 dengan Peraturan Pemerintah no. 23 tahun 2018. Hasil penelitian dalam penerapan Undang - Undang no. 36 tahun 2008 tidak semua biaya dapat dikurangkan menjadi pengurang perhitungan Pajak Penghasilan, biaya pajak tersebut harus memenuhi unsur 3M (Mendapatkan, Memelihara, Menagih) penghasilan. Biaya pajak berdasarkan PP no. 23 tahun 2018 (0,5\% dari omset) lebih murah dibandingkan dengan biaya pajak berdasarkan UU no. 36 tahun 2008 (rata-rata 1,15\% dari omset). Saat yang tepat dalam pelaksanaan kewajiban perpajakan berdasarkan PP no. 23 tahun 2008 adalah pada saat perusahaan tersebut berdiri dan beroperasi.
\end{abstract}

\begin{abstract}
The purpose of this study is to analyze the understanding of the Regulations Government number 23 of 2018 and Law number 36 of 2008, analyze the comparison of income tax costs based on Government Regulation number 23 of 2018 with Law number 36 of 2008, analyzing implementation of these regulations and analyze the right time to implement Government Regulation number 23 of 2018 and Law number 36 of 2008.

This study uses a qualitative approach, namely research techniques by analyzing tax reporting based on Law number 36 of 2008 with Government Regulation number 23 of 2018. The results of the research in the application of Law No. 36 of 2008 are not all costs can be deducted as a deduction from the calculation of Income Tax, the tax costs must meet the 3M elements (Obtaining, Maintaining, Collecting) income. Tax costs based on Government Regulation number 23 of 2018 (0.5\% of turnover) are cheaper than tax costs based on Law number 36 of 2008 (an average of $1.15 \%$ of turnover). The right time for the implementation of tax obligations under PP number 23 of 2008 is when the company is established and operating.
\end{abstract}

\footnotetext{
${ }^{\square}$ Alamat korespondensi:

Fakultas Ekonomika dan Bisnis, Universitas Semarang

Email: kesi@usm.ac.id
} 


\section{PENDAHULUAN}

Pajak merupakan iuran rakyat kepada kas negara berdasarkan Undang - Undang yang dapat dipaksakan dengan tiada mendapat imbal balik secara langsung dapat ditujukan dan yang digunakan untuk membayar pengeluaran umum. (Mardiasmo, 2011)

Selain itu pengertian pajak menurut Undang - Undang nomor 28 Tahun 2007, pajak merupakan kontribusi wajib kepada negara yang terutang oleh pribadi atau badan yang bersifat memaksa berdasarkan undang - undang tanpa mendapatkan imbalan secara langsung dan digunakan untuk keperluan negara bagi sebesar-besarnya kemakmuran rakyat. (ORTAX, 2010)

Pengertian pajak menurut Wajib Pajak (Pengusaha), pajak merupakan kewajiban yang harus dibayarkan kepada pemerintah sehingga mengurangi laba / keuntungan Wajib Pajak (Pengusaha). (Citra et al, 2016) Dengan adanya pemikiran bahwa pajak merupakan biaya yang akan mengurangi laba, wajib pajak cenderung melakukan penghematan dengan cara yang ilegal / tidak sesuai dengan aturan yang berlaku sehingga cenderung melakukan penggelapan pajak. Menurut (Putra, 2017) Penggelapan pajak merupakan usaha untuk memperkecil jumlah pajak yang terutang atau menggeser beban pajak yang terutang dengan melanggar ketentuan-ketentuan pajak yang berlaku.

Otoritas pajak hingga saat ini, telah beberapa kali melakukan perubahan peraturanperaturan untuk memudahkan Wajib Pajak dalam pelaksanaan kewajiban perpajakan, salah satunya dengan perubahan terakhir Peraturan Pemerintah no. 23 Tahun 2018 tentang Pajak Penghasilan Atas Penghasilan Dari Usaha Yang Diterima Atau Diperoleh Wajib Pajak Yang Memiliki Peredaran Bruto Tertentu. Di dalam Peraturan Pemerintah no. 23 Tahun 2018 Pasal 2 ayat 2, Wajib Pajak dimudahkan dalam perhitungan penyetoran pajak sebesar $0,5 \%$ dari omset (peredaran bruto). Hal ini dikarenakan sistem perpajakan di Negara Kesatuan Republik Indonesia menganut self assesment system, dimana sistem ini memberikan peran serta lebih kepada Wajib Pajak untuk menghitung, membayarkan dan menyetorkan secara mandiri. Pajak (fiskus) hanya berperan sebagai pengawas pelaksanaan kewajiban pajak dari Wajib Pajak.

Berikut tarif pajak berdasarkan Peraturan Pemerintah no. 23 Tahun 2018 dengan Undang - Undang no. 36 Tahun 2008 Tentang Pajak Penghasilan :

Tabel 1. Tarif Pajak

\begin{tabular}{lcc}
\hline \multicolumn{1}{c}{ Peredaran Usaha } & $\begin{array}{c}\text { PP no. 23 } \\
\text { Tahun 2018 }\end{array}$ & $\begin{array}{c}\text { UU no. 36 } \\
\text { Tahun } \\
\text { 2008 }\end{array}$ \\
\hline 0 s.d 4,8 Milyar & $0.5 \%$ & $12.5 \%$ \\
4,8 Milyar - 50 Milyar & - & $25 \%$ \\
Lebih dari 50 Milyar & - & $25 \%$ \\
\hline
\end{tabular}

Sumber: Pemerintah Indonesia, 2018 (Republik

Indonesia, 2008)

\section{TINJAUAN PUSTAKA}

\section{Pengertian perencanaan pajak}

Perencanaan pajak adalah langkah awal dalam manajemen pajak. Pada tahap ini dilakukan pengumpulan dan penelitian terhadap peraturan perpajakan agar dapat diseleksi jenis tindakan penghematan pajak yang akan dilakukan. (Suandy, 2008) sedangkan menurut (Jofita Meida Kadariyanty, Dwi Suhartini, 2012) Perencanaan pajak adalah merupakan tindakan penstrukturan yang terkait dengan konsekuensi potensi pajaknya, yang tekanannya kepada pengendalian setiap transaksi yang ada konsekuensi pajaknya dan menurut (Aditama \& Purwaningsih, 2014) Perencanaan pajak merupakan bagian manajemen pajak dan merupakan langkah awal di dalam melakukan manajemen pajak.

Berdasarkan pendapat para pakar tentang pengertian perencanaan pajak diatas, dapat disimpulkan perencanaan pajak adalah suatu tindakan dalam manajemen pajak yang terkait dengan pengendalian setiap transaksi yang memiliki konsekuensi pajak dalam melakukan penghematan pajak secara legal sesuai dengan peraturan pajak yang berlaku.

\section{Perananan perencanaan pajak}

Perencanaan Pajak bagi sebuah perusahaan merupakan satu hal yang penting yang harus dilakukan oleh persusahaan sekurang-kurangnya setahun sekali untuk 
mengalisa/mengevaluasi hasil perencanaan pajak kepada para pemakainya. Seperti, Pemegang Saham : Membutuhkan informasi perencanaan pajak terkait jumlah pajak secara efisien, efektif dan ekonomis yang akan dibayarkan oleh perusahaan telah sesuai dengan ketentuan perundangan-undangan, Direksi : Membutuhkan informasi perencanaan pajak untuk meningkatkan kinerja perusahaan dengan cara yang sesuai dengan peraturan perpajakan yang berlaku, Karyawan Bagian Pajak : Membutuhkan informasi terkait kewajiban pelaporan surat pemberitahuan pajak yang harus dilaksanakan setelah dievaluasi berdasarkan perencanaan pajak perusahaan.

\section{Komponen perencanaan pajak}

Tahapan dalam Perencanaan Pajak dimulai langkah-langkah sebagai berikut : menganalisa informasi yang ada, membuat satu atau lebih model kemungkinan jumlah pajak, mengevaluasi pelaksanaan perencanaan pajak, mencari kelemahan dan memperbaiki kembali rencana pajak, memutakhirkan perencanaan pajak.

Dalam dunia usaha sering kali perencanaan pajak dianggap sebagai tax evasion (penggelapan pajak) yang diartikan sebagai suatu skema memperkecil pajak terutang dengan cara melanggar ketentuan perpajakan yang berlaku. Misalnya dengan cara tidak melaporkan sebagian penjualan atau memperbesar biaya secara fiktif (tidak sesungguhnya).

Pelaksanaan peraturan perpajakan, Wajib Pajak diperkenankan memilih tarif yang sesuai dengan kondisi usaha Wajib Pajak. Di dalam memilih tarif yang sesuai dengan kondisi usaha, Wajib Pajak perlu melakukan perencanaan pajak.

Dalam perencanaan pajak, Wajib Pajak perlu mengetahui peraturan atau perundangundangan perpajakan yang berlaku saat ini, seperti : Undang - Undang nomor 36 Tahun 2008 Tentang Pajak Penghasilan (PPh) dan Peraturan Pemerintah nomor 23 Tahun 2018 Tentang Pajak Penghasilan (PPh) atas penghasilan dari usaha yang diterima atau diperoleh Wajib Pajak yang memiliki peredaran bruto tertentu.
Menurut pasal 17 ayat 2a UndangUndang nomor 36 Tahun 2008 Tentang Pajak Penghasilan ( $\mathrm{PPh}$ ) disebutkan bahwa tarif pajak penghasilan Wajib Pajak badan adalah sebesar 25\%. Sedangkan menurut pasal 2 ayat 2 Peraturan Pemerintah nomor 23 Tahun 2018 Tentang Pajak Penghasilan (PPh) atas penghasilan dari usaha yang diterima atau diperoleh Wajib Pajak yang memiliki peredaran bruto tertentu disebutkan bahwa tarif pajak penghasilan adalah sebesar $0,5 \%$.

\section{Kebijakan perencanaan pajak dalam manajemen laba}

Prinsip manajemen laba merupakan suatu tindakan yang dijalankan oleh manajemen perusahaan guna menaikkan atau menurunkan keuntungan (laba) dalam laporan keuangan eksternal. (Citra et al, 2016) Yaitu salah satunya dengan melakukan perencanaan pajak : memilih tarif pajak yang murah dan sesuai kondisi perusahaan. Dalam ilmu manajemen, laba merupakan suatu cerminan dari keberhasilan atau kegagalan suatu perusahaan dalam melaksanakan kegiatan ekonomi.

Semakin tinggi laba yang diperoleh, semakin bagus perusahaan dalam memanage kegiatan usahanya. Informasi laba yang diperoleh suatu laporan keuangan sangat penting, khususnya bagi mereka yang menggunakan laporan keuangan guna keperluan dalam pengambilan keputusan. Menurut teori keagenan, "antara pemilik (investor) dengan agen (manajemen) terjadi konflik kepentingan guna memaksimalkan utilitas masing-masing." (Aditama \& Purwaningsih, 2014)

Dari dasar tersebut memunculkan tanda tanya atas laba yang disajikan oleh pihak manajemen, maka kualitas dari suatu laba perusahaan sangat diperhatikan oleh penggunanya. Namun dalam menyusun laporan keuangan sebagai mana diatur dalam PSAK dilakukan oleh pihak manajemen, sehingga manajemen memungkinkan bertindak atas dasar kepentingannya atau dikenal dengan istilah manajemen laba. 


\section{METODE PENELITIAN}

Jenis penelitian

Penelitian kualitatif atau naturalistik adalah penelitian yang berhubungan dengan penelitian lapangan dan memfokuskan pada suatu makna, gambaran, pengertian, karakteristik, simbol dan pemaparan sesuatu. (Salim \& Syahrum, 2012) Berdasarkan pengertian diatas penelitian ini termasuk dalam penelitian kualitatif.

\section{Jenis dan sumber data}

Jenis data yang digunakan dalam penelitian ini adalah data kualitatif, yaitu jenis data yang dikumpulkan melalui wawancara, analisa dokumen dan observasi penelitian lapangan dan data kuantitatif berupa laporan keuangan beserta laporan perpajakan.

Sumber data dari penelitian ini adalah data primer dan sekunder, data primer yaitu berupa hasil interview dengan narasumber atas pertanyaan yang diajukan dalam wawancara secara lisan maupun tertulis sedangkan data sekunder yaitu berupa studi pustaka, penelaah kasus laporan keuangan dan laporan perpajakan.

\section{Teknik analisis data}

Metode analisis data yang dipergunakan di dalam penelitian ini adalah metode analisis deskriptif, yaitu penelitian yang menggambarkan suatu hasil penelitian namun hasil gambaran penelitian tidak digunakan untuk mengambil kesimpulan yang lebih umum.

\section{ANALISIS DATA DAN PEMBAHASAN}

\section{Analisis data}

Laporan keuangan tahun 2018 dibuat berdasarkan UU no. 36 tahun 2008 harus dikoreksi terlebih dahulu sesuai dengan ketentuan peraturan perpajakan sehingga menjadi laporan keuangan fiskal yang dapat digunakan menjadi dasar perhitungan Pajak Peghasilan (PPh) badan.

Apabila laporan keuangan tahun 2018 dibuat berdasarkan PP no. 23 tahun 2018 perhitungan Pajak Penghasilannya ( $\mathrm{PPh})$ dihitung dari omset penjualan setiap bulannya dikali tarif $0,5 \%$ dan disetorkan maksimal tanggal 15 bulan berikutnya.

Pembahasan

Di bawah ini akan dibahas langkah langkah penyusunan perhitungan dan laporan keuangan berdasarkan UU no. 36 Tahun 2008 dan PP no. 23 Tahun 2018 :

1. Penyusunan Laporan Keuangan Fiskal

Dalam menyusun laporan keuangan fiskal dan menghitung $\mathrm{PPh}$ terhutang berdasarkan UU no. 36 Tahun 2008, langkah - langkah dalam penyusunannya adalah sbb :

a. Data Intern Perusahaan

Dalam menyusun perhitungan dan laporan pajak perusahaan, data-data yang diperlukan :

1. Dokumen transaksi

2. Buku besar laporan keuangan

3. Daftar penyusutan aktiva tetap

4. Daftar pembayaran pajak perusahaan dan pelaporan pajak masa (bulanan).

b. Kertas Kerja

Setelah data intern terkumpul, kertas kerja disusun berdasarkan peraturan UU no. 36 Tahun 2008 seperti biaya apa saja yang dapat dibebankan (deductible expense) dan mengkoreksi biaya yang tidak dapat dibebankan (non deductible expense) kemudian menghitung $\mathrm{PPh}$ terhutang seperti dalam Tabel 2.

Dari perhitungan PPh Badan di atas, selama tahun 2018 harus membayar $\mathrm{PPh}$ Badan sejumlah Rp. 27.363.125,-. Dan untuk tahun 2019, setiap bulannya wajib menganggarkan angsuran $\mathrm{PPh}$ Pasal 25 sejumlah Rp. 2.280.259,-

$\mathrm{PPh} 25$ sejumlah Rp. 2.280.259,- yang dibayarkan tidak berpengaruh terhadap kenaikkan atau penurunan omset / penjualan usaha. Dikarenakan dasar perhitungannya dari PPh Badan terhutang tahun sebelumnya dibagi 12 bulan.

c. Laba Rugi berdasarkan UU no. 36 Tahun 2008 dengan Laba Rugi berdasarkan PP no. 23 Tahun 2018

Dari perhitungan PPh Badan berdasarkan PP no. 23 Tahun 2018, wajib membayar PPh Badan selama Tahun 2018 sejumlah Rp17.615.368. 
Untuk tahun 2019, tidak perlu menganggarkan $\mathrm{PPh} 25$ seperti perhitungan $\mathrm{PPh}$ berdasarkan UU no. 36 Tahun 2008.
Tetapi hanya berdasarkan dari Omset dikalikan dengan tarif $0.5 \%$.

Tabel 2. Kertas Kerja LR Fiskal Per. 1 Januari s.d 31 Desember 2018

\begin{tabular}{|c|c|c|c|c|}
\hline \multirow[t]{2}{*}{ Keterangan } & \multirow[t]{2}{*}{ LR Komersiil } & \multicolumn{2}{|c|}{ Koreksi Fiskal } & \multirow[t]{2}{*}{ LR Fiskal } \\
\hline & & Positif & Negatif & \\
\hline Penjualan & 2.387 .540 .175 & & & 2.387.540.175 \\
\hline Persediaan Awal & 0 & & & 0 \\
\hline Pembelian & 2.277 .875 .020 & & & 2.277 .875 .020 \\
\hline Persediaan Akhir & $(511.235 .000)$ & & & $(511.235 .000)$ \\
\hline Harga Pokok Penjualan & $(1.766 .640 .020)$ & & & $(1.766 .640 .020)$ \\
\hline Laba Kotor & 620.900 .155 & & & 620.900 .155 \\
\hline B. Gaji Karyawan & $(182.990 .000)$ & & & (182.990.000) \\
\hline B. BPJS - Kesahatan & $(11.704 .500)$ & & & $(11.704 .500)$ \\
\hline B. BPJS - Ketenagakerjaan & (19.156.378) & & & (19.156.378) \\
\hline B. Telepon & $(4.962 .800)$ & & & $(4.962 .800)$ \\
\hline B. Listrik & $(15.563 .850)$ & & & $(15.563 .850)$ \\
\hline B. Keperluan Kantor & $(8.206 .550)$ & 8.206 .550 & & 0 \\
\hline B. Sewa & (20.000.000) & & & (20.000.000) \\
\hline B. Penys. Peralatan Kantor & $(9.876 .800)$ & & & $(9.876 .800)$ \\
\hline Total Biaya U \& A & $(272.460 .878)$ & & & $(264.254 .328)$ \\
\hline B. Penys. Kendaraan & $(11.000 .000)$ & 5.500 .000 & & $(5.500 .000)$ \\
\hline B. Transport & $(209.630 .000)$ & 99.785 .300 & & $(109.844 .700)$ \\
\hline B. Tol / Parkir / Retribusi & $(42.563 .000)$ & 20.535 .000 & & $(22.028 .000)$ \\
\hline Total Biaya Penjualan & $(263.193 .000)$ & & & $(137.372 .700)$ \\
\hline Laba Usaha & 85.246 .277 & & & 219.273.127 \\
\hline Pend. Jasa Giro & 242.377 & & 242.377 & 0 \\
\hline Beban Jasa Giro & $(367.500)$ & & & $(367.500)$ \\
\hline Beban Pajak Jasa Giro & $(48.475)$ & 48.475 & & 0 \\
\hline Pend/(Beban) Di Luar & $(173.599)$ & & & $(367.500)$ \\
\hline Usaha & & & & \\
\hline Laba Tahun Berjalan & 85.072 .679 & & & 218.905 .627 \\
\hline $\begin{array}{l}\text { Pajak Penghasilan } \\
=218.905 .000 \times 12.5 \%\end{array}$ & $(27.363 .125)$ & & & \\
\hline
\end{tabular}


Tabel 3. LR berdasarkan UU no. 36 Tahun 2008 dan PP no. 23 Tahun 2018 Per. 1 Januari s.d 31

\begin{tabular}{|c|c|c|}
\hline \multicolumn{3}{|c|}{ Desember 2018} \\
\hline Keterangan & $\begin{array}{l}\text { LR berdasarkan UU no. } 36 \\
\text { Tahun } 2008\end{array}$ & $\begin{array}{l}\text { LR berdasarkan PP no. } \\
23 \text { Tahun } 2018\end{array}$ \\
\hline Penjualan & 2.387 .540 .175 & 2.387 .540 .175 \\
\hline Persediaan Awal & 0 & 0 \\
\hline Pembelian & 2.277 .875 .020 & 2.277 .875 .020 \\
\hline Persediaan Akhir & $(511.235 .000)$ & $(511.235 .000)$ \\
\hline Harga Pokok Penjualan & $(1.766 .640 .020)$ & $(1.766 .640 .020)$ \\
\hline Laba Kotor & 620.900 .155 & 620.900 .155 \\
\hline B. Gaji Karyawan & $(182.990 .000)$ & $(182.990 .000)$ \\
\hline B. BPJS - Kesahatan & (11.704.500) & $(11.704 .500)$ \\
\hline B. BPJS - Ketenagakerjaan & (19.156.378) & (19.156.378) \\
\hline B. Telepon & $(4.962 .800)$ & $(4.962 .800)$ \\
\hline B. Listrik & $(15.563 .850)$ & $(15.563 .850)$ \\
\hline B. Keperluan Kantor & $(8.206 .550)$ & $(8.206 .550)$ \\
\hline B. Sewa & (20.000.000) & $(20.000 .000)$ \\
\hline B. Penys. Peralatan Kantor & $(9.876 .800)$ & $(9.876 .800)$ \\
\hline Total Biaya U \& A & $(272.460 .878)$ & $(272.460 .878)$ \\
\hline B. Penys. Kendaraan & $(11.000 .000)$ & $(11.000 .000)$ \\
\hline B. Transport & (209.630.000) & $(209.630 .000)$ \\
\hline B. Tol / Parkir / Retribusi & $(42.563 .000)$ & $(42.563 .000)$ \\
\hline Total Biaya Penjualan & $(263.193 .000)$ & $(263.193 .000)$ \\
\hline Laba Usaha & 85.246 .277 & 85.246 .277 \\
\hline Pend. Jasa Giro & 242.377 & 242.377 \\
\hline Beban Jasa Giro & $(367.500)$ & $(367.500)$ \\
\hline Beban Pajak Jasa Giro & $(48.475)$ & $(48.475)$ \\
\hline Pend/(Beban) Di Luar Usaha & $(173.599)$ & $(173.599)$ \\
\hline Laba Tahun Berjalan & 85.072 .679 & 85.072 .679 \\
\hline Pajak Penghasilan & $(27.363 .125)$ & \\
\hline & & $(17.615 .368)$ \\
\hline
\end{tabular}



Laba Setlah Pajak 57.709.554
67.457 .311
Penghasilan

Berdasarkan wawancara dengan narasumber 1 selaku direktur, narasumber 2 selaku manajer keuangan dan pajak, dan narasumber 3 selaku staff pajak adalah sbb :

Narasumber 1 selaku direktur, hanya mengetahui secara garis besar saja mengenai peraturan UU no. 36 Tahun 2008 dan PP no. 23 Tahun 2018. Yang diketahui narasumber 1 mengenai UU no. 36 Tahun 2008 yaitu semakin besar biaya yang dikeluarkan semakin kecil pajak yang dibayarkan, sedangkan PP no. 23 Tahun 2018 yaitu tarif $\mathrm{PPh} 0.5 \%$. Narasumber 1 mengetahui UU no. 36 Tahun 2008 dan PP no. 23 Tahun 2018 dari konsultan pajak dan karyawan. Menurut narasumber 1 kendala yang dihadapi jika menerapkan UU no. 36 Tahun 2008 dan PP no. 23 Tahun 2018 adalah tarif yang dikenakan di PP no. 23 Tahun 2018 terlalu mahal $(0.5 \%$ dari omset $)$ sedangkan kendala yang dihadapi jika menerapkan UU no. 36 Tahun 2008 yaitu terlalu repot mengumpulkan nota biaya-biaya. Narasumber 1 menganggap PPh lebih murah berdasarkan UU no. 36 Tahun 2008 dibandingkan dengan PP no. 23 Tahun 2018. Untuk perkembangan peraturan perpajakan berbentuk sosialisasi dan lain - lain yang lebih mengetahui narasumber 2 .

Narasumber 2 selaku manajer keuangan dan pajak, mengetahui mengenai peraturan UU no. 36 Tahun 2008 dan PP no. 23 Tahun 2018. Yang diketahui narasumber 2 mengenai UU no. 36 Tahun 2008 yaitu perhitungannya laba kena pajak dikali $12.5 \%$ dan untuk menghitung laba kena pajak perlu dikoreksi biaya-biaya / akun yang tidak ada hubungannya dengan kegiatan usaha, Sedangkan PP no. 23 Tahun 2018 yaitu omset dikali tarif $0.5 \%$ dan perusahaan tetap perlu membuat laporan keuangan tetapi tidak dilakukan koreksi pajak. Narasumber 2 mengetahui peraturan perpajakan UU no. 36 Tahun 2008 dan PP no. 23 Tahun 2018 dari konsultan pajak, sosialisasi KPP, internet dan AR pajak. Menurut narasumber 2 kendala yang dihadapi jika menerapkan PP no. 23 Tahun 2018, pimpinan keberatan karena biaya pajak yang dibayarkan terlalu besar. Narasumber 2 melihat pelaporan yang sudah terjadi lebih murah menggunakan PP no. 23 Tahun 2018 dibandingkan dengan UU no. 36 Tahun 2008. Sedangkan untuk perkembangan peraturan perpajakan berbentuk sosialisasi dan lain - lain, staff mendapat informasi dari konsultan, narasumber 2 juga memperoleh dari konsultan, AR pajak dan sosialisasi dari KPP.

Narasumber 3 selaku staff pajak, sedikit mengetahui mengenai UU no. 36 Tahun 2008 dan tidak mengetahui PP no. 23 Tahun 2018. Yang diketahui narasumber 3 mengenai UU no. 36 Tahun 2008 yaitu menginput biayabiaya. Narasumber 3 mengetahui UU no. 36 Tahun 2008 dan PP no. 23 Tahun 2018 dari konsultan dan manajer. Kendala yang dihadapi narasumber 3 selama ini dalam penerapan UU no. 36 Tahun 2008 adalah biaya yang diinput banyak sekali. Narasumber 3 tidak mengetahui lebih hemat antara biaya pajak menurut UU no. 36 Tahun 2008 dengan PP no. 23 Tahun 2018. Narasumber 3 mendapat wawasan pengetahuan pajak dari konsultan dan manajer.

Tidak semua memahami secara detail isi dari peraturan perpajakan PP no. 23 Tahun 2018 dan UU no. 36 Tahun 2008, pengetahuan hanya secara garis besar mengenai PP no. 23 adalah PPh Final 0,5\% dan UU no.36 Tahun 2008 perlu mengumpulkan bukti - bukti biaya untuk mengurangi $\mathrm{PPh}$ terhutang.Pengetahuan dan informasi mengenai peraturan - peraturan perpajakan diperoleh dari konsultan, AR pajak, internet dan sosialisasi dari Kantor

Pelayanan Pajak (KPP). Dalam peraturan UU no. 36 Tahun 2008 kendala yang dihadapi adalah banyaknya biaya (bukti-bukti) yang perlu diinput untuk menghitung dan melaporkan SPT Tahunan sehingga merepotkan Wajib Pajak, sedangkan PP no. 23 Tahun 2018 kendala yang dihadapi adalah biaya pajak yang terlalu mahal dari sisi 
pengusaha (Wajib Pajak). Walaupun demikian perhitungan dan pelaporan pajak merupakan kewajiban yang mutlak sebagaai warga negara, kewaajiban itu dimulai saat perusahaan berdiri dan beroperasi.

\section{SIMPULAN}

Dalam penerapan UU no. 36 Tahun 2008, tidak semua biaya dapat dibebankan menjadi pengurang laba yang menjadi dasar perhitungan Pajak Penghasilan. Biaya yang dapat dibebankan harus menggunakan prinsip 3M (Mendapatkan, Menagih dan Memelihara) penghasilan sehingga biaya yang tidak memenuhi prinsip 3M (Mendapatkan, Menagih dan Memelihara) penghasilan harus dilakukan koreksi pajak. Dengan adanya koreksi pajak tersebut berakibat pada kenaikkan laba yang menjadi dasar perhitungan $\mathrm{PPh}$ terhutang tahun 2018 berakibat berkurangnya laba bersih setelah pajak perusahaan.

Biaya pajak berdasarkan PP no. 23 Tahun 2018, lebih murah diterapkan dibandingkan dengan biaya pajak berdasarkan UU no. 36 Tahun 2008. Biaya pajak berdasarkan PP no. 23 Tahun 2018 dengan tarif rata-rata $0,5 \%$ dari penjualan kotor, sedangkan biaya pajak berdasarkan UU no. 36 Tahun 2008 tarif rata-rata sebesar $1,15 \%$ dari penjualan kotor.

\section{DAFTAR PUSTAKA}

Aditama, F., \& Purwaningsih, A. (2014). PENGARUH PERENCANAAN PAJAK TERHADAP MANAJEMEN LABA PADA PERUSAHAAN NONMANUFAKTUR YANG TERDAFTAR DI BURSA EFEK INDONESIA. MODUS, 26(1). Retrieved from www.pajak.

Citra et al. (2016). The Effect of Current Deffered Tax Asset, Deffered Tax Expense and Tax Planning On Earnings Management. JOM Fekon (Vol. 3).

Jofita Meida Kadariyanty, Dwi Suhartini, T. T. (2012). ANALISIS FAKTOR FAKTOR YANG MEMOTIVASI MANAJEMEN PERUSAHAAN MELAKUKAN TAX PLANNING, 4(1), 19-34.
Mardiasmo. (2011). Perpajakan. (Andi, Ed.) (Revisi 201). Yogyakarta: CV. Andi Offset.

ORTAX. (2010). PENGERTIAN PAJAK. Retrieved from https://www.ortax.org/ortax/?mod=fo rum\&page $=$ show\&idtopik $=12839$

Pemerintah Indonesia. Peraturan Pemerintah No. 23 (2018).

Putra, B. A. (2017). Faculty of Economics Riau University ,. JOMFekom, 4(1), 843-857.

Republik Indonesia. Undang - Undang No. 36 (2008). Indonesia.

Salim, \& Syahrum. (2012). Metodologi Penelitian Kualitatif. (Haidir, Ed.), Rake Sarasin. Bandung: Citapustaka Media. Retrieved from https://scholar.google.com/citations?u ser $=\mathrm{O}-\mathrm{B} 3 \mathrm{eJYAAAAJ} \& \mathrm{hl}=\mathrm{en}$

Suandy, E. (2008). Perencanaan Pajak. (M. Teresa, Ed.) (4th ed.). Jakarta: Salemba Empat. 